\title{
Analysis of Self-Regulated Learning Skills in Senior High School Students: A Phenomenological Study
}

\author{
Ameliasari Tauresia Kesuma ${ }^{1}$, Heri Retnawati ${ }^{1}$, Himawan Putranta ${ }^{2}$ \\ ${ }^{1}$ Department of Education Research and Evaluation, Graduate School, Yogyakarta State University, \\ Yogyakarta 55281, Indonesia \\ ${ }^{2}$ Department of Educational Sciences, Concentration of Physics Education, Graduate School, Yogyakarta \\ State University, Yogyakarta 55281, Indonesia
}

\begin{abstract}
The purpose of this research is to analyze self-regulated learning (SRL) level of senior high school students. This research is qualitative research with a phenomenological approach. The research sample consisted of 21 high school students who were selected using purposive sampling technique. Data collection techniques are used in-depth interviews to reveal participant experiences related to SRL. Data analysis techniques are done by using Creswell's analysis model that uses the stages of data collection, reduction, and interpretation. The results showed that several main themes were found that support the SRL skills that senior high school students have to possess, including the preparation phase, performance, and the reflection. To be able to develop SRL skills senior high school students, the school, teachers, and parents need to provide opportunities for exploration to students in order to gain knowledge and solve problems on their own. Students also need to be given the freedom to arrange their learning process by their goals.
\end{abstract}

Keywords - Performance, preparation, reflection, self-regulated learning.

DOI: $10.18421 /$ TEM103-35

https://doi.org/10.18421/TEM103-35

Corresponding author: Ameliasari Tauresia Kesuma, Department of Education Research and Evaluation, Graduate School, Yogyakarta State University, Yogyakarta 55281, Indonesia.

Email: ameliasaritauresia.2018@student.uny.ac.id

Received: 10 October 2020.

Revised: 27 June 2021.

Accepted: 05 July 2021.

Published: 27 August 2021.

(cc) BY-Nc-ND]C 2021 Ameliasari Tauresia Kesuma, Heri Retnawati \& Himawan Putranta; published by UIKTEN. This work is licensed under the Creative Commons Attribution-NonCommercial-NoDerivs 4.0 License.

The article is published with Open Access at www.temjournal.com

\section{Introduction}

Senior high school students in cognitive and mental development have different phases than junior high school and elementary school students. Senior high school students have entered a period of adolescent transition that can already think critically and abstractly [1]. Good self-management will affect the competence of both in terms of cognitive intelligence or emotional intelligence. The development phase of senior high school students enters the transition from adolescence to early adulthood. At this time, a person has begun to think openly, flexibly, and adaptably [2]. The early adult phase is usually marked by conditions of uncertainty, instability in dealing with a problem. Early adulthood is a time when a person experiences physical and mental changes simultaneously [3]. Characteristics of early adulthood related to the educational process are the period of self-regulation learning. These conditions have an impact on how students can have self-regulation skills in learning. Consequently, applied learning has to support students' selfregulation learning skills.

These conditions illustrate that senior high school students have to have good self-regulation learning skills to deal with problems in life, especially in the world of education independently. Students are required to learn independently, be smart in managing time, and carry out more intensive and targeted learning activities so that students are more productive, creative, and innovative [4]. On the other hand, mastery of senior high school student skills in self-regulation is still immature. One's skills can be obtained by teaching and learning. The transmission of skills with practice has proven to be effective in developing skills [5]. The role of the teacher in developing self-regulation learning skills is very important. Students who get good mentoring from teachers can identify their strengths and weaknesses, while students who do not get good teacher 
assistance will tend to lead to slower development of self-regulation.

Self-regulation skills are needed by students to solve the problems encountered in learning. Selfregulation learning is considered as a component in shaping student identity. Self-regulation learning is part of lifelong learning. The concept of selfregulation learning emphasizes developing a sense of responsibility and making your own decisions [6]. Self-regulation learning skills tend to teach individuals to be able to diagnose their learning needs, formulate goals, identify human and material resources for learning, choose and apply appropriate learning [7]. Based on the problem, it can be identified about the existing problems, namely the existence of self-regulated learning skills that have to be possessed by senior high school students. This experience-based learning model aims to improve learning outcomes. Intensive assistance and practice in making decisions in dealing with problems is a basic skill that students have to master [8]. These competencies become the basic skills that will help high school students in developing holistic competencies. Meanwhile, to limit the problems that arise, this research is focused on the forms of selfregulation learning skills.

One of the important aspects for students in learning is the ability to manage themselves in learning or self-regulated learning. Students are required to have good self-regulated learning skills to assist in the learning process. Self-regulation in learning is a cognitive approach to learning strategies. Self-regulated learning is very important for many people today. Problems for students can be rated from simple to complex ones such as lack of focus in learning, student failure in achieving brilliant learning achievements, and the influence of peers on negative things. Following the aim to study independently throughout his life, senior high school students have a big challenge to be able to do good self-regulation [9]. Self-regulated learning is proven to have a major role and influence in high school students. Self-regulated learning has a significant relationship with academic achievement in senior high school students. Self-regulated learning also has a relationship with the readiness to face exams.

High emotional intelligence can also influence in increasing students' academic presentations. The environment such as family also contributes to the development of self-regulated learning for students. Parents teach and support self-regulated learning through modeling, encouraging, facilitating rewards goal setting, using good strategies, and other processes [10]. Students who learn by self-regulation not only know what is needed by each task, but they can also implement the strategies needed. They can read at a glance or carefully. They can use various memory strategies or organize the material. When they become more knowledgeable (have or show a lot of knowledge, awareness, or intelligence) in a field, they apply many strategies automatically [11]. The demand to achieve successful learning and learning status requires students to be able to identify the skills they have. The ability to identify this is a fundamental problem for senior high school students. In this research, trying to explore the students' skills in self-regulation learning based on learning obtained and the influence of other factors around them.

Understanding the importance of self-regulation learning skills for students in improving their competence, this study will specifically explore the forms of self-regulation learning for senior high school students. This research tries to answer the following questions,

a. What form of self-regulation learning skills should senior high school students have?

b. What are the constraints faced by students in developing self-regulation learning skills?

\section{Methods}

\subsection{Research Design}

This research uses a phenomenological approach to explain the general meaning of some individuals regarding their life experiences. Phenomenology is the study of the essence and the treatment carried out. It starts from each problem which is further defined in essence, the essence of perception, and essence of consciousness for example [12]. Researchers collected data from participants who had experienced the phenomenon and developed a combined description of the essence of the experience for all participants, and this description consists of what they experienced and how they experienced it. The purpose of phenomenology is to extract the essence of the various experiences of participants when they experience a phenomenon such as a difficulty concentrating in learning, emotional difficulties, and others [13]. This research focuses on the description of the participants' experiences. The experience referred to in this research is about the skills of senior high school students in managing or organizing themselves about school learning.

\subsection{Participant}

Participants in this research were students aged 1518 years from various cities in Indonesia, including Semarang, Yogyakarta, Jakarta, and Padang. The sample in this research was taken with a purposive technique, where the participant categories were predetermined namely senior high school students who came from public schools, schools that used the 
method of self-regulated learning, boarding schools, and homeschooling. This age was chosen because students are considered to have experience in managing the learning process, have experienced successes and failures, and students are in middle age who can still improve their self-regulated learning skills [14]. The number of participants was 21 students with a ratio of 4 male students and 17 female students. Furthermore, to facilitate, maintain, and protect the privacy of participants, participants are given an identity using their initials. Therefore, the detailed characteristics of the participants who contributed to this research can be seen in Table 1 .

Table 1. Participant Demographic Profiles

\begin{tabular}{|c|c|c|c|c|}
\hline \multirow{2}{*}{ No. } & \multirow{2}{*}{ Name } & \multirow{2}{*}{ School } & \multicolumn{2}{|c|}{ Gender } \\
\hline & & & Male & Female \\
\hline 1. & R1 & Public School & $\mathrm{X}$ & \\
\hline 2. & $\mathrm{R} 2$ & Public School & $\mathrm{X}$ & \\
\hline 3 & R3 & Public School & & $\mathrm{X}$ \\
\hline 4 & R4 & Public School & & $\mathrm{X}$ \\
\hline 5 & R5 & Public School & & $\mathrm{X}$ \\
\hline 6 & R6 & Public School & & $\mathrm{X}$ \\
\hline 7 & R7 & Public School & & $\mathrm{X}$ \\
\hline 8 & R8 & School-based SRL & $\mathrm{X}$ & \\
\hline 9 & R9 & School-based SRL & $\mathrm{X}$ & \\
\hline 10 & R10 & School-based SRL & & $\mathrm{X}$ \\
\hline 11 & R11 & School-based SRL & & $\mathrm{X}$ \\
\hline 12 & R12 & School-based SRL & & $\mathrm{X}$ \\
\hline 13 & R13 & School-based SRL & & $\mathrm{X}$ \\
\hline 14 & R14 & $\begin{array}{c}\text { Islamic boarding } \\
\text { school }\end{array}$ & & $\mathrm{X}$ \\
\hline 15 & R15 & $\begin{array}{c}\text { Islamic boarding } \\
\text { school }\end{array}$ & & $\mathrm{X}$ \\
\hline 16 & R16 & $\begin{array}{c}\text { Islamic boarding } \\
\text { school }\end{array}$ & & $\mathrm{X}$ \\
\hline 17 & R17 & $\begin{array}{c}\text { Islamic boarding } \\
\text { school }\end{array}$ & & $\mathrm{X}$ \\
\hline 18 & R18 & Homeschooling & & $\mathrm{X}$ \\
\hline 19 & R19 & Homeschooling & & $\mathrm{X}$ \\
\hline 20 & R20 & Homeschooling & & $\mathrm{X}$ \\
\hline 21 & R21 & Homeschooling & & $\mathrm{X}$ \\
\hline
\end{tabular}

Note: SLR stands for self-regulated learning

Besides, before conducting data collection, researchers established relationships with participants involved in this research. The researchers did this to get an agreement, and so that the research was easier to carry out the data collection process. This research was conducted from November 2019 until January 2020. This research begins with the initial observation stage as one of the data collection techniques to determine student characteristics first.

\subsection{Instruments and Procedures}

The next stage, researchers continued with indepth interviews with participants to get more information related to students' self-regulated learning skills. The procedure for implementing the data collection was carried out after permission was obtained from the school through the school principal. Data collection in this study was carried out through in-depth individual interviews. In-depth interviews are conducted in a duration of 45 to 60 minutes. In-depth interviews are generally conducted at participating schools, but some participants are willing to conduct interviews in their homes. Considering the quality of the recorded interview, the researcher proposes to participants that the interview should be conducted indoors to minimize unwanted noise. Interview questions are open and general, compiled by researchers to understand the core phenomena of this study [15]. During the interview, the researchers tried to create a conducive climate that made the participants feel comfortable and free in responding to every question raised. The researcher avoids questions that have the potential to open sensitive information and are difficult for participants to answer. All interview results are recorded with a recording device to get quality data.

\subsection{Data Analysis}

Following the analysis model presented by Creswell and Creswell, data analysis is conducted through data collection, data reduction, and data interpretation [13]. After the data is obtained then the researcher transcribes verbatim with the help of the atlas.ti program. The interview data transcript was then coded according to the theme and sentence that were considered as important points to be analyzed. The transcript data that is written is then read and examined repeatedly to get keywords following the research theme. Every sentence that is considered important is then made an important statement or phrase. The important phrases are then reduced in certain themes according to the discussion. The meaning in this particular theme is then integrated into one big theme by making a deep and complete description. The final stage is the data interpretation by linking and explaining the reduction results according to the themes. The final step is to validate the data. Validation is done to check the results of the analysis to the informant. Based on the results of the analysis then crosschecked back to the informants is done to determine the compatibility of the data with the results of the analysis. If there are relevant new findings from the data then they can be included in the final description. 


\section{Results and Discussion}

Following the basic concepts in self-regulated learning, the skills in self-regulated are useful for senior high school students in facing examinations, increasing self-confidence, high anxiety, fear in understanding what is learned, and worrying about not graduating. The habit is only to receive and carry out instructions from the teacher without thinking about the benefits and effects, without being trained to think critically, causing students not to have selfregulated learning skills to overcome the problems they face during the learning process.

\subsection{The Concept of Self-Regulated Learning}

Self-regulated learning (SRL) includes cognitive, metacognitive, behavioral, motivational, and emotional aspects of learning [16]. SRL is a broad field that provides a variety of things to understand variables that influence student learning and learning outcomes (for example, self-efficacy, volition, and cognitive strategies) which can be learned in a comprehensive and holistic approach. According to Alvi and Gillies, SRL places a focus on how students activate, change, and maintain their ways of learning and how they relate to their social environment, in the context of formal and informal teaching. Learning is not something that happens to students, but something that happens by students and scientists states that for learning to occur, students have to be proactive. SRL is a proactive process of students to obtain academic skills, the proactive process, for example having an appropriate strategy, and monitoring the process of implementing the strategy to see its effectiveness [17].

Recent research reveals many aspects of SRL that highlight the need to study this phenomenon in real and real-time contexts, as an event or aptitude. Aptitude is a relatively enduring trait and this aptitude measurement can be used to predict the behavior of an individual in the future. Thus, the metacognitive and cognitive perception of a person becomes an accurate measurement of self-regulated learning [18]. Self-regulated learning as an innate aptitude can be measured through quantitative methods. SRL is an activity, a constructive process whereby students create learning goals and in the process of achieving these goals, students monitor, regulate, control cognitive abilities, motivation and behavior and are all limited to the learning goals that have been set and the learning environment [19]. Bandura proposes 3 steps of self-regulation, which includes self-observation, about us seeing ourselves, our behavior, and guarding it. Decision is comparing what is seen with a standard. Besides, self-response that is if we are better in comparison with our standards, we reward ourselves for our answers.
Pintrich defines SRL as an active, constructive process, where students set their learning goals and then monitor, regulate, and control their cognition, motivation, and behavior, guided by their goals and contextual terms of the environment [20]. SRL is generally characterized as active participants who efficiently control their own learning experiences in different ways, including determining a productive work environment and using resources effectively, organizing and training information to learn, maintaining positive emotions during the process learning, and maintaining positive motivation about their abilities. Pintrich added that self-regulation strategies in learning generally include three types of strategies, namely cognitive regulation strategies, motivational regulation strategies, and behavioral academic regulation strategies [21]. Cognitive regulation is the information processing strategy of cognitive and metacognitive activities from the simplest memory, to more complicated strategies.

Individuals who deal with stress and emotions, failure to achieve success in learning to use motivational regulations. Motivational regulation can influence thinking, behavior that influences the choice of something. Behavioral regulation according to Pintrich is an aspect of self-regulation that involves an individual's efforts to control his actions and behavior [22]. Managing time, managing the learning environment, and seeking help are examples of behavioral regulation. This is supported by the statement of participant $\mathrm{R} 1$, regarding the learning process in the class, "I often don't have the desire to learn, because the lessons are too many and difficult". R7 participants also added that "I can't think that is difficult, so if the lesson makes me dizzy then I usually stay quiet or not pay attention".

SRL is generally characterized as active participants who efficiently control their own learning experiences in different ways, including determining a productive work environment and using resources effectively, organizing and training information to learn, maintaining positive emotions during assignments academic tasks, and maintain positive motivational beliefs. Based on the various expert opinions, it can be synthesized SRL is how students have the awareness to set their learning, starting from the learning objectives to be achieved, how students achieve their learning goals, and how students reflect evaluate whether the process has been effective or not to achieve self-determined learning goals. The results of students depending on the learning environment and student level are better and support the learning environment, the ability of students to make self-regulation better, as well as the higher the age of students, the more students realize their learning needs, the better they manage their learning. Four aspects can improve SRL in students, 
namely giving students the freedom to determine their learning choices, giving students the freedom to collaborate, giving support to new knowledge and skills they want to develop, and giving their confidence to do feedback [23]. This makes them aware of their ability to always solve the problems they face. Teacher readiness is needed to be able to train SRL skills on students. Teachers need to increase their knowledge about various characteristics of students and their learning styles.

\subsection{Traditional Class}

The frequency of words that are often mentioned by students who participated in this study are learning, teachers, school, lessons, and assignments. This shows that student learning is inseparable from the teacher, school, lessons, and assignments. Furthermore, their statements regarding learning in traditional classrooms can be shown in Figure 1 below.



Figure 1. Traditional class patterns

In traditional classes, the role of the teacher is very dominant, controlling and controlling the teacher does everything, so students do not know the importance of learning, except because of the teacher's orders. The purpose of learning in traditional classrooms is still abstract, such as to gain knowledge, to make parents happy, as well as learning motivation. As stated by partisans R14, "I learn if it is intent, quiet if it is not crowded, at home; but if there is a daily exam only given 15 minutes before the exams, if it is busy cannot learn, I cannot focus". Traditional classes tend to make students anxious, because their learning goals are to get good grades on exams, as participants R16 stated, "I have dropped too because, during the exams, we should need enough rest, I force myself to study continue to learn continuously, so instead drop, before the exams were a week even sick".

Zimmerman revealed SRL is divided into three phases, forethought, performance, and reflection [24]. In this research, it was found that traditional classes would have difficulty entering the SRL cycle. This is because there is a contradiction, where students who are accustomed to waiting for learning instructions, have to determine their own learning goals and how they learn so that the pattern of concepts as shown in Figure 2 below.

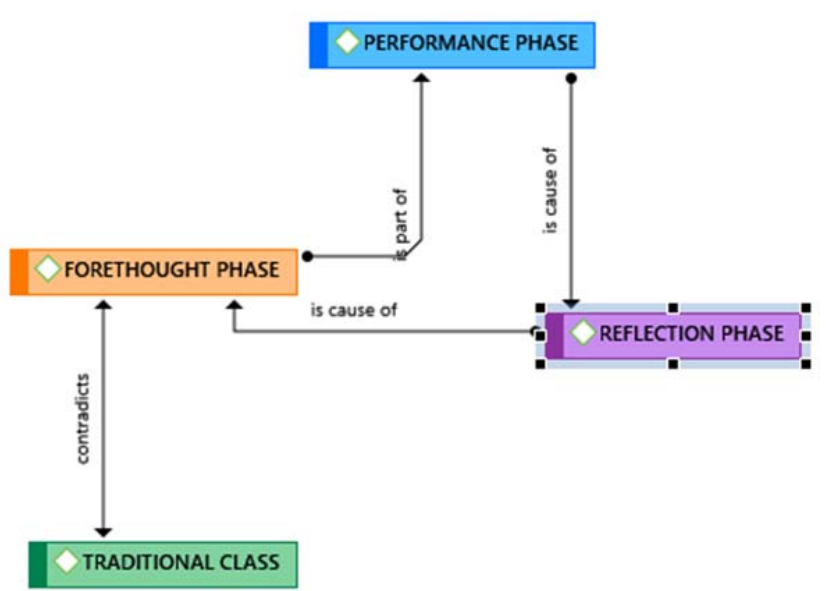

Figure 2. Patterns of traditional class relation with the self-regulated learning cycle

Traditional classes are classes that generally occur in schools, students tend to depend on the teacher to obtain information. They expect their teachers to provide learning material, motivate them, and take responsibility for the learning process. Teachers have to largely control what is being learned, how it is learned when it is learned, and to what extent it will be learned. Generally, accepted patterns of roles in which the teacher conveys declarative and procedural knowledge, and students have to find ways to understand, store, and activate knowledge that leads to situations where students do not have enough time and opportunity to organize themselves on how they will learn. This then leaves students, during the learning process, to depend on what has been provided and arranged by the teacher.

This condition is similar to what was conveyed by R9 participants who stated, "Often the teacher gives a lot of lessons so that we have to say a little difficulty, it takes time and concentration". Participant R6 also said, "For lessons outside of arithmetic such as religion, sometimes we are only told, not given examples that we can understand further". Most learning that begins in the traditional classroom learning tends to be fragmented, indirect experience, based on the goals set by the teacher. A systematically planned and planned learning experience cannot attract students' interest, because students to activate prior knowledge cannot use the information provided [25]. There are several reasons why SRL is more difficult to do in a class context. First, most students assume that the teacher's role is to provide relevant resources and motivate them to engage in learning activities.

Such role beliefs are difficult to change and hamper the SRL process, especially since most students do not have a clear concept of their needs and desires to acquire new knowledge and skills, because according to them acquiring knowledge and skills is not an urgent need. What usually happens teachers have to convince students that the 
opportunities they offer are unique opportunities to gain valuable skills and knowledge. Teachers are very dominant in traditional classes, they have to convince their students of the importance of knowledge and skills to be acquired, learning the teacher and all commitments set goals and regulations are made to achieve the learning goals set by the teacher. As revealed by Kalu, learning tends to be fragmented, based on the goals set by the teacher. One participant suggested that the participant had never felt learning in school that allowed him to discuss something, all the learning processes have been arranged by the teacher, so students are reluctant to interact with the teacher.

Furthermore, R8 participants said, "I was never the best at school till today; I was the guy who sits at the edge of the room and listening to the teacher from a distance. This recall to me as a way to avoid interaction with the teacher and the attention of the class. However, I have been to multiple schools and most of them were to be "academic" where we study and learn, but not to discuss. From my understanding, the best way to understand something is to discuss and understand the flaws of a teacher or student'. Students do not know the importance of learning, they learn when there are homework and assignments, and learning vary according to their intentions and mood. The role of the teacher is very dominant; a subject is liked if the teacher is fun to say, not because they need knowledge from the subject. Students like this will have difficulty when they have to start deciding something on their own. The question then arises to whether this SRL skill can be trained to students.

When viewed in the preparation phase students tend to have abstract and general learning goals, such as happy parents, studying, and it has nothing to do with what they will learn. In contrast to students who have SRL skills, their learning goals are clearer, to produce paintings of high artistic value, to find out profitable business methods, to answer questions about nature. This clear learning goal will make it easier for students to find material and determine how to learn [26]. The performance phase or where learning activities are carried out as a process of achieving learning goals, this is influenced by motivation, how they control whether the process is carried out according to the initial plan, how environmental conditions support them in processing, managing their time, and know when they need help. Not all of these learning activities are carried out in traditional classes because students tend to be confused in arranging study schedules with so many subject matters that they are required to master. In the last phase of reflection, conducted with daily tests or formative tests made by the teacher, which is conducted to determine the level of student understanding of the subject matter that has been taught.

Reflection is not done to find out whether the learning process carried out can help students achieve their learning goals. SRL skills can be improved if students are given autonomy to manage their learning. Self-regulated learning (SRL) as thoughts, feelings, and actions produced by students are oriented systematically towards the achievement of their learning goals [27]. This definition implies that to be able to develop SRL skills effectively students have to be given the freedom to arrange their learning process according to their goals. As a homeschooler (R18) participant put it, "There are so many strange and unique things in the world, and I am curious about various things. Only the surface level is okay, but what is important is that I understand enough. Enough to understand this world, to survive. If I am interested in something, it is not hard to turn into real research. "Layers of seawater", "His friends", or "Chocolate". Honestly, trivia is quite stupid, but I am interested. Besides, I have a tool that can answer stupid questions with just a few touches. My main study is mathematics and English, which I do whenever I have time. Usually when I'm bored, what I do is open my math learning website". Homeschooler participants have never been involved with traditional classes, school systems, and teachers, and they are given the freedom to determine their own learning goals, what they want to know, choose their way of learning and how it will reflect. The three constructs are the core of this self-arranged definition of learning, namely, episodes of learning, self-learning goals, and process goals [28].

\subsection{Preparation Phase}

In the preparation phase or the forethought, phase consists of two elements, namely first, how they convince themselves that the task or learning process they are going to do is useful, the second is how students analyze the task or learning process that was planned. In this phase students who have SRL skills show learning objectives clearer as stated by participant R14 that, "I want to let you know that if we need experience, we need to be experienced, in my opinion not all lessons are in school, meaning sometimes like lessons like talking. Don't you learn, do not have to be at school, if my family values are experienced, you do not have high grades either, it's okay you have effort. I want to tell you that you need to take the experience to receive great knowledge, like encouraging me to do this, make a travel trailer". Furthermore, participant R3 also stated, "Yet, I prefer to create my own company that is based on aerospace, how human can travel to march or other planets". The learning motivation is also 
obtained from self-confidence with the learning process chosen to achieve the learning objectives as stated by participant R16 that, "I love watching videos on YouTube, most often I watch about doctors, doctors, operations like that, how to sew like that. I want to go to medicine". Based on the results of the interview in the preparatory phase showed that there were main themes that emerged and they were considered important such as confidence in self, orientation to goals, self-concept, interests, and goals. Therefore, more detail can be explained in Figure 3 below.



Figure 3. Preparation phase patterns in the self-regulated learning cycle

\subsection{Performance Phase}

After the preparation phase, students begin to do learning activities following what they plan and enter the performance phase or the learning process phase is carried out. In this phase, there are 4 main aspects, namely self-observation, environmental conditions, and self-control, or self-monitoring. In this phase, we will see the difference between students who are accustomed to independent learning (with SRL skills) and traditional classroom students (where the teacher's role is very dominant). The condition of the traditional classroom environment in which the teacher's role is very dominant, students learn depending on how the teacher's performance is done in the class. As expressed by participant R15 that, "What the teacher likes is comfortable, sometimes just giving a question like that, if you explain it, you don't understand, and if you explain it that much". Furthermore, R12 participants stated, "Teachers are good teachers, they teach almost all of them, I like the way they teach. Sometimes, some teachers are not liked by my friends, because of being boring, then it goes too far like this, yeah that's it. However, for me to think positively like maybe the reason for this teacher is like this, I don't want to think anything strange about that teacher".

Students learn independently, have environmental conditions that support whatever they do, as does the opinion of R10 participants who state, "They will always support me and fill the gaps to which I am missing of. They will help me if I am in worry of my findings or a particular subject that I am lacking. Even, to talk about my absurd theory that they might understand or not. To me, they are a helping role in my life and a person to talk to. Not everyone might accept this and not everyone might listen to me. To be communicating all of this has been a huge help for $m e "$. Likewise, parental support as well as the R14 participant's opinion that "If I, mom always say just go through everything, like for example like in school, I already know that I like art, not everyone like hundreds of percents like, oh you are an art child, you are good at design, you are good at English. I am also confused, where do I get my interest. But yes, my mother said, just run it all, o yes you are good at English, just do it, but it turns out that after running it turns out I don't like it, what for example, run design, like pictures, there is this, then suddenly there is math, it's hard, right? I don't like it". In this phase, several important themes can be obtained from the results of the interview, such as self-motivation, the need for help from the others, time management, and others. Furthermore, Figure 4 below shows these important themes.

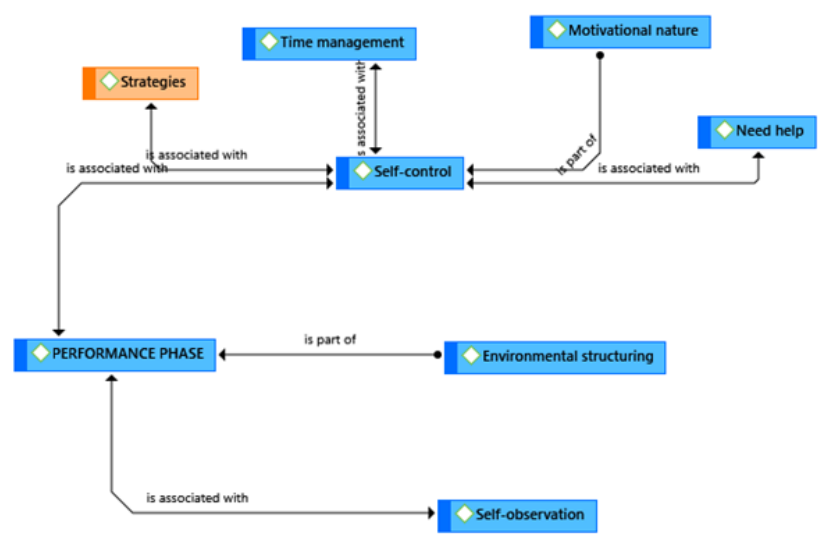

Figure 4. Performance phases patterns in the selfregulated learning cycle

Traditional class students usually study because there is homework or assignments from the teacher, or because they have to face daily tests that will be approaching. As stated by participant R12 that, "I learn sometimes, if it's the person who memorizes, memorizes biology, how much is memorized several times, when everything is finished, if it counts learning the material, look at the sample questions, then work on the problems. The study is late at night 9-10, when I intend to study 3 hours 4 hours I feel at home, usually when studying when I have homework". While students who are accustomed to independent learning, have different learning strategies, they learn what they like the way they like too, as stated by R19 participants said that "Layers of seawater", "Em-dash and his friends", or "Chocolate". Honestly, trivia is quite stupid, but I am interested. After all, I have a tool that can answer 
stupid questions with just a few touches". Traditional class students do not have the natural motivation to learn, learn because parents or teachers tell them otherwise, they do not learn. Meanwhile, independent learning students have a high curiosity and know the benefits they will get when learning something, as does the statement expressed by R21 participants that, "If I'm interested in something, it's not difficult to turn into real research".

\subsection{Reflection Phase}

During the reflection phase, students assess the results of the learning process that has been done, whether or not by the goals that have been determined in the preparation phase. This reflection phase is divided into two aspects, namely selfreaction and self-assessment that are interrelated; the aspect of self-reaction in this study is the student's self-satisfaction on the achievements he gained in the learning process. The self-assessment aspect consists of self-evaluation and causal attribution (how students can explain why it fails why it works). Students' self-satisfaction with SRL skills is no longer a grade or score because they learn not for that, but the benefits of what they learn, for their lives. As one R 17 participant said, "There are so many strange and unique things in the world, and I am curious about various things. Only the surface level is okay, but what is important is that I understand enough. Enough to understand this world, to survive". Likewise, when they assess themselves and explain why they have not succeeded in understanding something, as the R18 participant said, "If I lived like this up and down my whole life, it would be difficult, when high school is exciting, when it is exciting, now from my observations, I also want, like my friends right now and just right first. We are mostly confused, what are we doing to learn like this, it takes a while to know that, not everyone immediately understands, we have to learn this because of this. What should that be, you don't need to fix what I think, just live it, if it's hard to meet later, you will also meet, if you want to meet your goals, then you will also find it".

The explanation why they fail for a traditional class student is an explanation why their numbers are bad in the test, as stated by R20 participants that, "Maybe for the future, there is something wrong from the beginning, learning is not optimal or what, then the prayer is lacking". When asked for selfevaluation, some students feel that evaluation should be comprehensive in all aspects including the teacher who has to also evaluate the teaching and learning process with their students. As stated by participant R19, "I prefer the teacher to grade a student, if he has his teaching grades. Why would you grade someone if the teacher itself has a bad grade on teaching, making it in math $X$ is not equal to $Y$. So please understand your work and grades, and then assess the other". Meanwhile, the elaboration of the reflection phase can be expressed in a scheme shown in Figure 5 below.

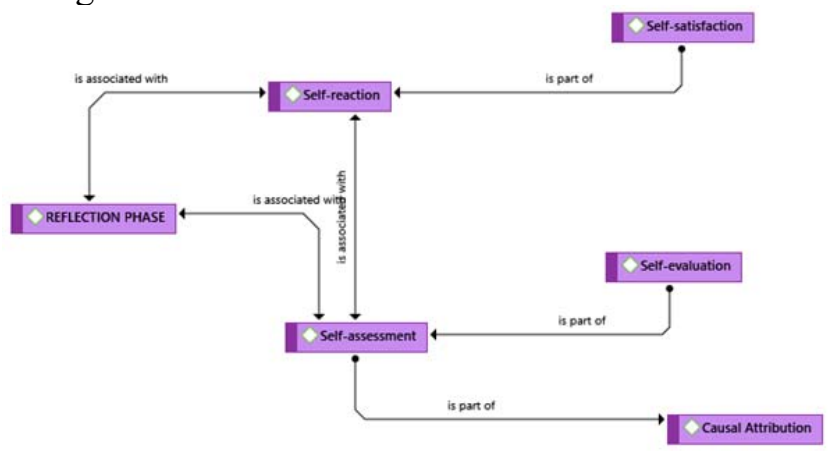

Figure 5. Reflection phase patterns in the self-regulated learning cycle

\section{Conclusion}

The conclusion of the research shows that students' skills in regulating themselves in the learning process are influenced by many factors such as teacher's support, task-oriented learning, intentional cooperative activities, and they have to be closely related to their lives or experience-based by using relevant, critical learning, and can be negotiated. The forms of skills that students have to possess include skills in preparing themselves, showing performance, and reflecting on the results obtained. Some obvious deficiencies exist informing high school students' self-regulated learning skills, for example, students still need technical direction to do something, lack of self-confidence inability, still do not know the importance of learning goals, emotional management, and others. Therefore, to improve self-regulated learning skills, students have to begin to be allowed to explore how to gain knowledge and solve their problems. Besides, to be able to develop SRL skills effectively students have to be given the freedom to arrange their learning process according to their goals.

\section{References}

[1]. Alotaibi, K., Tohmaz, R., \& Jabak, O. (2017). The relationship between self-regulated learning and academic achievement for a sample of community college students at King Saud University. Education Journal, 6(1), 28-37.

[2]. Blazek, J. D., Cooper, G. L., Judd, M. V., Roper, R. J., \& Marrs, K. A. (2013). Trying out genes for size: Experiential learning in the high school classroom. The american biology Teacher, 75(9), 657-662. 
[3]. Vandsburger, E., Duncan-Daston, R., Akerson, E., \& Dillon, T. (2010). The effects of poverty simulation, an experiential learning modality, on students' understanding of life in poverty. Journal of Teaching in Social Work, 30(3), 300-316.

[4]. Kormos, J., \& Csizer, K. (2014). The interaction of motivation, self-regulatory strategies, and autonomous learning behavior in different learner groups. Tesol quarterly, 48(2), 275-299.

[5]. Small, W. (2014). The transmission of skill. Philosophical Topics, 42(1), 85-111.

[6]. Gu, P., Zhang, Y., \& Gu, H. (2020). Creating a technology-enhanced constructivist learning environment for research ability development in a BA Thesis Writing course. Computer Assisted Language Learning, 33(5-6), 538-566.

[7]. Sawatsky, A. P., Ratelle, J. T., Bonnes, S. L., Egginton, J. S., \& Beckman, T. J. (2017). A model of self-directed learning in internal medicine residency: a qualitative study using grounded theory. BMC medical education, 17(1), 1-9.

[8]. Davis, D. S., \& Neitzel, C. (2011). A self-regulated learning perspective on middle grades classroom assessment. The Journal of Educational Research, 104(3), 202-215.

[9]. Jansen, R. S., Van Leeuwen, A., Janssen, J., Jak, S., \& Kester, L. (2019). Self-regulated learning partially mediates the effect of self-regulated learning interventions on achievement in higher education: A meta-analysis. Educational Research Review, 28, 100292.

[10]. Pfister, R., Dignath, D., Hommel, B., \& Kunde, W. (2013). It takes two to imitate: Anticipation and imitation in social interaction. Psychological Science, 24(10), 2117-2121.

[11]. Madihie, A., \& Mos, Z. (2018). The relation between self-regulated learning, academic performance of graduate student. COUNS-EDU: The International Journal of Counseling and Education, 3(2), 63-68.

[12]. Moustakas, C. (1994). Phenomenological research: Analyses and examples. Phenomenological research methods, 120-154.

[13]. Creswell, J. W., \& Creswell, J. D. (2017). Research design: Qualitative, quantitative, and mixed methods approaches. Sage publications.

[14]. Oates, S. (2019, September). The importance of autonomous, self-regulated learning in primary initial teacher training. In Frontiers in Education (Vol. 4, p. 102). Frontiers.

[15]. Creswell, J. W., \& Poth, C. N. (2016). Qualitative inquiry and research design: Choosing among five approaches. Sage publications.

[16]. Ben-Eliyahu, A. (2019). Academic Emotional Learning: A critical component of self-regulated learning in the emotional learning cycle. Educational Psychologist, 54(2), 84-105.

[17]. Alvi, E., \& Gillies, R. M. (2020). Teachers and the teaching of self-regulated learning (SRL): The emergence of an integrative, ecological model of SRL-in-context. Education Sciences, 10(4), 98.
[18]. Bergey, B. W., Parrila, R. K., Laroche, A., \& Deacon, S. H. (2019). Effects of peer-led training on academic self-efficacy, study strategies, and academic performance for first-year university students with and without reading difficulties. Contemporary Educational Psychology, 56, 25-39.

[19]. Sachs, R., Akiyama, Y., \& Nakatsukasa, K. (2019). The value of introspective measures in aptitudetreatment interaction research: A window on individual differences in action. Journal of Second Language Studies, 2(2), 336-364.

[20]. Arifin, S. A. S., Retnawati, H., Mailool, J., \& Putranta, H. (2020). The factors that influence of reading ability the Hijaiyah alphabet on pre-school children. Journal for the Education of Gifted Young Scientists, 8(2), 667-680.

[21]. Heirweg, S., De Smul, M., Devos, G., \& Van Keer, H. (2019). Profiling upper primary school students' self-regulated learning through self-report questionnaires and think-aloud protocol analysis. Learning and Individual Differences, 70, 155-168.

[22]. Musso, M. F., Boekaerts, M., Segers, M., \& Cascallar, E. C. (2019). Individual differences in basic cognitive processes and self-regulated learning: Their interaction effects on math performance. Learning and Individual Differences, 71, 58-70.

[23]. Zheng, J., Xing, W., Zhu, G., Chen, G., Zhao, H., \& Xie, C. (2020). Profiling self-regulation behaviors in STEM learning of engineering design. Computers \& Education, 143, 103669.

[24]. Kolovelonis, A., Goudas, M., \& Samara, E. (2020). The Effects of a Self-Regulated Learning Teaching Unit on Students' Performance Calibration, Goal Attainment, and Attributions in Physical Education. The Journal of Experimental Education, $1-18$.

[25]. Callan, G. L., \& Cleary, T. J. (2019). Examining cyclical phase relations and predictive influences of self-regulated learning processes on mathematics task performance. Metacognition and Learning, 14(1), 43-63.

[26]. Kalu, M. E. (2019). How does "subjective I" influence a qualitative research question, theoretical approach and methodologies?. Global Journal of Pure and Applied Sciences, 25(1), 97-101.

[27]. Winne, P. H. (2010). Improving measurements of self-regulated learning. Educational psychologist, 45(4), 267-276.

[28]. Cerezo, R., Bogarín, A., Esteban, M., \& Romero, C. (2020). Process mining for self-regulated learning assessment in e-learning. Journal of Computing in Higher Education, 32(1), 74-88. 